\title{
Falésia de Cajueiro da Praia: testemunho da dinâmica da costa piauiense
}

\author{
Cajueiro da Praia cliff: testimony of the dynamics of the piauiense coast
}

SILVA $^{1}$, C. H. S.; LIMA ${ }^{2}$, I. M. M. F.

carlos-henriquess@hotmail.com

\begin{abstract}
Resumo
O Piauí possui a menor zona costeira do Brasil, com uma linha de apenas $66 \mathrm{~km}$ de extensão, representando apenas 0,89\% do total brasileiro. Apesar disso, apresenta feições geomorfológicas singulares, tendo destaque a falésia de Cajueiro da Praia, única nesse litoral. É formada pelo afloramento Barreiras no contato com o mar piauiense, próximo ao limite leste do Piauí com o Estado do Ceará. O desenvolvimento desta pesquisa envolveu revisão da literatura; trabalhos de campo; registro fotográfico e utilização de fichas de registro dos elementos e processos atuantes na área. Os resultados encontrados indicaram que essa falésia se compõe de sedimentos da Formação Barreiras, do terciário, recoberta por uma delgada camada de sedimentos quaternários. Conclui-se que os agentes costeiros são os principais responsáveis por sua evolução recente, por não ter sido identificadas interferências de uso antrópico nesse local. Sua dinâmica está representada por um terraço de abrasão, constituídos por clastos de quartzo e quartzito e óxidos/ hidróxidos de ferro, evidenciando a retrogradação atual da linha de costa.
\end{abstract}

Palavras-chave: Falésia; Morfodinâmica Costeira; Linha de Costa; Piauí.

\begin{abstract}
Piauí has the smallest coastal zone in Brazil, with a line of only $66 \mathrm{~km}$ in length, representing only $0,89 \%$ of the Brazilian total. Despite this, it presents unique geomorphological features, highlighting the cliff of Cajueiro da Praia, unique in this coast. It is formed by the outcrop Barreiras in contact with the piauiense sea, near the eastern limit of Piauí with the State of Ceará. The development of this research involved a review of the literature; field work; photographic record and use of records of the elements and processes that operate in the area. The results indicate that this cliff is composed of sediments of the tertiary, Formação Barreiras, covered by a thin layer of quaternary sediments. It is concluded that coastal agents are mainly responsible for their recent evolution, since no interferences of anthropic use in this place were identified. Its dynamics is represented by a terrace of abrasion, consisting of quartz and quartzite clasts and iron oxides / hydroxides, evidencing the current retrogradation of the coastline.
\end{abstract}

Keywords: Cliff; Coastal Morphodynamics; Coastline; Piauí.

\section{INTRODUÇÃO}

O Piauí possui a menor zona costeira do Brasil, localizada na porção norte do Estado, nordeste setentrional do Brasil. Apresenta uma linha de apenas $66 \mathrm{~km}$ de extensão, com direção geral de Oeste-Leste, iniciando-se na baía das Canárias - Delta do rio Parnaíba, fazendo o limite com o Estado do Maranhão e se estendendo até a baía onde desagua o rio Ubatuba, no limite

${ }^{1}$ Carlos Henrique Santos da Silva, Instituto Maranhense de Estudos Socioeconômicos e Cartográficos, Secretaria de Estado de Programas Estratégicos, São Luís-MA, Brasil.

${ }^{2}$ Iracilde Maria de Moura Fé Lima, Departamento de Geografia e História, Universidade Federal do Piauí, Teresina-PI, Brasil. 
com o Ceará, bem próximo de onde se localiza a falésia de Cajueiro da Praia, objeto deste estudo.

Apesar de sua pequena extensão, essa faixa costeira se apresenta como um dos laboratórios naturais, que fornece indícios significativos sobre a dinâmica de oscilações do nível do mar, em tempos passados e atuais. Constitui-se, assim, um campo de estudos passível de compreensão dos fatores intrínsecos e extrínsecos, que influenciaram suas mudanças através do tempo, o que subsidia estudos diversos e inter-relacionados, uma vez que esta zona costeira responde de imediato às variações no nível de base (SILVA; LIMA, 2017).

Como zona de interface entre a terra e o mar, esta área apresenta alto grau de complexidade e de sensibilidade ambiental, sendo, portanto, extremamente frágil, conformando sistemas deposicionais efêmeros, tanto espacial, quanto temporal, o que gera morfologias variadas que estão em constante estado de mudança (ROSSETI, 2008). São exemplos dessa dinâmica a presença de ilhas fluviomarinhas, dunas fixas e móveis, praias, estuários e também a única falésia ativa na costa do Piauí, a de Cajueiro da Praia.

As falésias costeiras são, portanto, superfícies de forte inclinação, onde a terra se encontra com o mar. Sua gênese está associada a processos geomorfológicos de primeira ordem de significância, que ocorrem ao longo de cerca de $80 \%$ das linhas de costas de todo o mundo (EMERY; KUHN, 1982).

A falésia é um termo indistintamente utilizado para designar as formas do relevo litorâneo abruptas ou escarpadas ou, ainda, desnivelamento de igual aspecto no interior do continente. Deve-se, no entanto, reservá-lo, exclusivamente, para definir tipos de costas nos quais o relevo aparece com fortes abruptos, sendo o trabalho do mar feito pelo solapamento da base, conforme Guerra e Guerra (2008).

Para Christofoletti (1980), a falésia é um ressalto não coberto pela vegetação, com declividade muito acentuada e de alturas variáveis, localizado na linha de contato entre a terra e o mar. Este autor destaca, ainda, que à medida que a falésia vai recuando para o continente, amplia-se a superfície erodida pelas ondas que é chamado de terraço de abrasão.

A erosão ou abrasão marinha é a principal responsável pelo retrocesso, evolução e configuração das costas, influenciada pelas ondulações e regimes de maré. Tal trabalho de destruição realizado pelas ondas e correntes, pode ser melhor observado nas falésias, onde as ondas carregadas de sedimentos são responsáveis pela erosão na base e eventual movimento de massa e recuo dessas morfologias (BLOOM, 1970).

Buscando ampliar o conhecimento da morfodinâmica da zona costeira do Piauí, estabeleceu-se como objetivo desta pesquisa estudar a dinâmica da falésia de Cajueiro da Praia, 
único afloramento do Barreiras na costa do Piauí. Como principal conclusão destacou-se que os agentes costeiros são os principais responsáveis pela evolução recente desta falésia, por não ter sido identificadas interferências de uso antrópico neste local. Assim, a dinâmica dessa feição do relevo está representada pela formação de um terraço de abrasão, constituído predominantemente por clastos de quartzo e óxido/ hidróxido de ferro, evidenciando a retrogradação atual da linha de costa.

\section{MATERIAL E MÉTODO}

Para a realização desta pesquisa utilizou-se a abordagem sistêmica, em função da complexidade dos processos que envolve a formação e dinâmica das falésias marinhas, principalmente por envolver vários materiais e processos na perspectiva de suas inter-relações de dependências mútuas e de seus aspectos funcionais (ROSS, 2006).

A abordagem sistêmica nos estudos geográficos possibilita a utilização de uma metodologia que abrange cronologia, métodos quantitativos e atividades humanas, destacando as relações entre as características dos elementos e as relações entre o meio ambiente e as características desses mesmos elementos. Tal abordagem se caracteriza como holística, levando em consideração que os sistemas dinâmicos, complexos e não-lineares abordam a grande diversidade dos elementos, com vários graus de liberdade quanto ao comportamento destes (GUERRA; MARÇAL, 2006).

O trabalho iniciou-se com o levantamento de publicações científicas e outros documentos com dados referentes à especificidade do tema em questão. A partir de então foram realizados trabalhos de campo, para reconhecimento e análise visual das feições e características morfológicas e geológicas, como tipos de sedimentos, cores, textura, estrutura, além da identificação de possíveis interferências antrópicas na dinâmica costeira natural, através do uso e ocupação da falésia e de seus registros através de fotografias.

Durante o trabalho de campo fez-se a aplicação de uma ficha, necessária a organização de dados sobre a feição, incluindo dados gerados durante a pesquisa, para posterior sistematização e análise de informações pertinentes à caracterização física; o possível uso e ocupação da falésia de Cajueiro da Praia e a identificação dos processos locais operantes. 


\section{RESULTADOS E DISCUSSÃO}

\subsection{Caracterização da área de estudo}

Quatro municípios do Piauí têm parte de suas áreas na faixa costeira, mas apenas em Cajueiro da Praia se encontra uma feição de relevo que se caracteriza como uma falésia.

A base geológica da área onde se encontra a falésia corresponde, predominantemente, às coberturas cenozoicas abrangendo os períodos Terciário e Quaternário. O Terciário está representado pela Formação Barreiras, composta por sedimentos arenoargilosos, não ou pouco litificados. Apresentam coloração ora avermelhada, ora creme ou amarelada, muitas vezes com aspecto mosqueado, mostrando horizontes conglomeráticos e níveis lateríticos, sem cota definida, em geral, associados à percolação de água subterrânea. O período Quaternário está representado por depósitos sedimentares de dunas fixas e móveis e também por sedimentos aluvionares (LIMA; BRANDÃO, 2010).

O clima característico da área de estudo é o Aw' - Tropical Chuvoso (quente e úmido com chuvas de verão e outono) de acordo com a proposta de Köppen (CAVALCANTI, 2000). Apresenta duas estações bem definidas, uma chuvosa, com concentração de chuvas no primeiro semestre, com distribuição média anual de aproximadamente $1300 \mathrm{~mm}$ e outra seca, predominante no segundo semestre. As temperaturas médias mensais variam entre $26,5^{\circ} \mathrm{C}$ e $27,5^{\circ} \mathrm{C}$. Os alísios de nordeste, são os principais tipos de ventos da área de estudo, apresentando velocidade absoluta entre 0,0 e 5,8 m/s (PAULA, 2013).

A costa do Piauí é regida pelo domínio de mesomarés com valores de amplitude que chegam a 3,7 metros de variação. Estas são do tipo semidiurna, que seguem o padrão normal de marés, com a ocorrência de duas preamares e duas baixa-mares no período de um dia lunar, ou seja, $24 \mathrm{~h} 50 \mathrm{~m}$. Os intervalos de tempo entre a preamar e a baixamar consecutiva de pouco mais de 6 horas (PAULA, 2013).

As ondas apresentam valores médios $0,83 \mathrm{~m}$ durante a estação seca e $0,64 \mathrm{~m}$ na estação chuvosa, sendo os valores mais altos na estação seca por estarem relacionados com a maior velocidade dos ventos durante este período. As ondas que atuam no litoral do Piauí chegam predominantemente do norte-nordeste $\left(340-10^{\circ}\right)$ e perto da costa são afetadas por rochas submersas, como recifes de arenito, causando a atenuação e a refração-difração das ondas. $\mathrm{O}$ período de pico de onda varia entre 5,8 e 12,4 s, sendo que mais de 70\% das ondas apresentam período entre 6 e 9 s durante a estação chuvosa e $90 \%$ do tempo durante a estação seca. As ondas swell (> 9 s período) são as mais significativas durante a estação chuvosa, chegando aproximadamente 25,7\% do tempo (PAULA et al., 2016). 
A corrente longitudinal é considerada a principal componente responsável pelo transporte de sedimentos na zona costeira. Assim, a sua variação é calculada a partir dos dados de incidência e altura das ondas na arrebentação, tendo sido encontrados valores de velocidade dessa corrente variando de $-1,02 \mathrm{~m} / \mathrm{s}$ (máxima para leste) a $8,87 \mathrm{~m} / \mathrm{s}$ (máxima para oeste), mas mantendo uma corrente média de 1,23m/s (PAULA et al., 2016).

A vegetação predominante nessa área se caracteriza por ser psamófila (psamobiomas), ou seja, que tem "preferência" por solos arenosos, envolvendo espécies arbóreas, arbustivas e rasteiras (AB’SÁBER, 2001). Há também ocorrência da Copernicia prunifera (carnaúba), principalmente nas faixas de contato das planícies fluviomarinhas com as dunas da área de entorno da falésia e até bem próximo dela, conforme se observou em campo.

\subsection{Análise da falésia de Cajueiro da Praia}

A falésia de Cajueiro da Praia apresenta cerca de 200 metros de extensão, tendo as seguintes coordenadas geográficas em seu ponto central: 0255'30" S e 41²0'09” W. Encontrase no Nordeste do município, em uma ponta que adentra pra o mar (Figura 1). É formada principalmente por sedimentos da Formação Barreiras, datados do paleógeno/neógeno, superpostos por depósitos arenosos quaternários decorrentes da movimentação de dunas e posterior estabilização desta, formando peleodunas e dunas mais recentes. Estas encontram-se fixadas pela vegetação predominantemente herbácea e por cajueiros, carnaúbas e coqueiros no seu entorno.

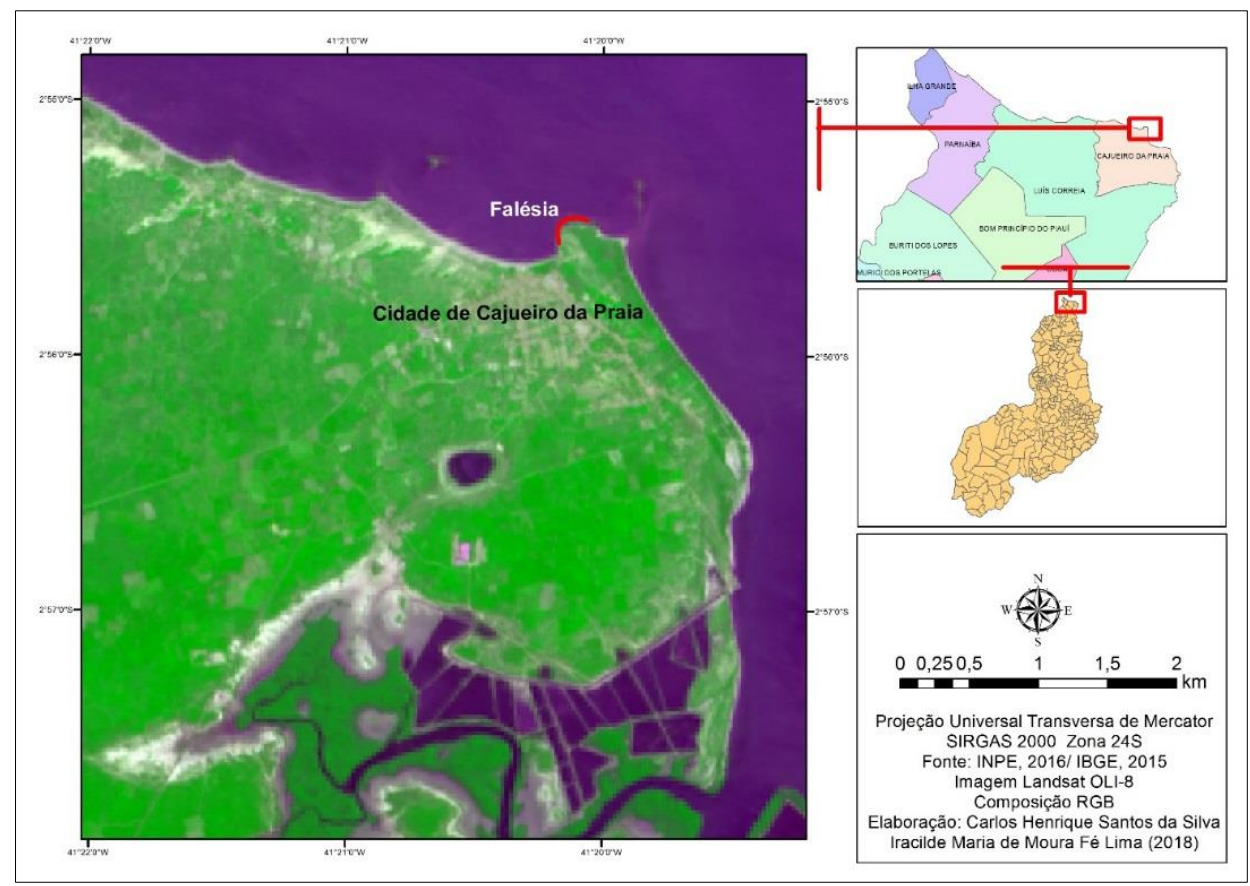

Figura 1: Mapa de localização da área de estudo. Fonte: Elaborado pelos autores (2018). 
Assim, estima-se que essa feição do relevo foi modelada/retrabalhada durante os últimos 6.000 anos, quando o mar ficou próximo do seu nível atual. Decorrente dos processos erosivos, impulsionados pelas oscilações do nível do mar e aceleração dos processos eólicos, representados ora pelo deslocamento e ora pela estabilidade de dunas no litoral piauiense, infere-se a existência de outras falésias presentes ao longo do litoral do Piauí foram totalmente desgastadas e/ou estabilizadas, sendo superpostas por dunas. Consequentemente o único resquício da Formação Barreiras que aflora na costa piauiense corresponde à falésia de Cajueiro da praia.

Assim, esta falésia se diferencia das demais encontradas no litoral do Brasil, principalmente pelas características de sua gênese e por representar uma relíquia geomorfológica no processo de evolução da costa brasileira, realçando sua singularidade (Figura 2).

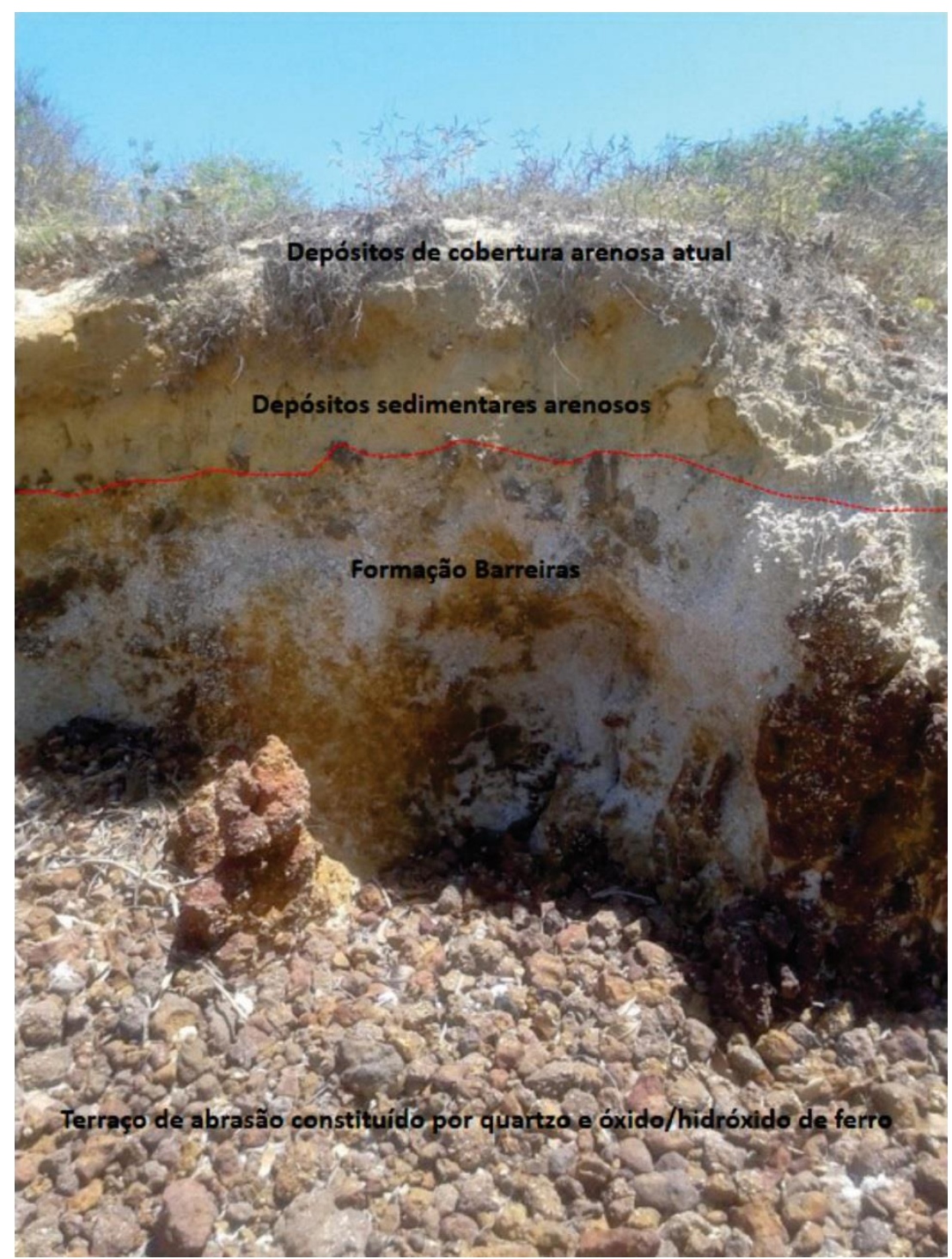

Figura 2: Constituição da Falésia de Cajueiro da Praia. Fonte: Foto dos autores (2016). 
A falésia de cajueiro da Praia apresenta um ângulo médio de inclinação > que $50^{\circ}$, com vertente íngreme, estendendo-se abruptamente da base até o contato com os depósitos quaternários constituídos por areias. Nos depósitos Barreiras, há a predominância de uma face única, pelítica, formada principalmente por arenitos finos e argilas homogêneas e caulínicas, mostrando colorações variegadas, com intervalos avermelhados a vinho, ligadas a presença de hematita, esbranquiçados a rósea e violáceos, possuindo alta plasticidade. Quando do seu contato com as águas do mar, por influência das ondas e marés, parte desta formação se consolida formando concreções ferruginosas nos interstícios dos pequenos blocos de sedimentos consolidados. Nos depósitos quaternários, ocorrem predominantemente areias finas e médias, por vezes mostrando coloração amarelada (RODRIGUES et al., 1994). Todos esses depósitos são muito suscetíveis a erosão por processos marinhos e eólicos, em decorrência de sua condição de pouca coesão/consolidação e cobertura vegetal rarefeita, como se observa na Figura 3.

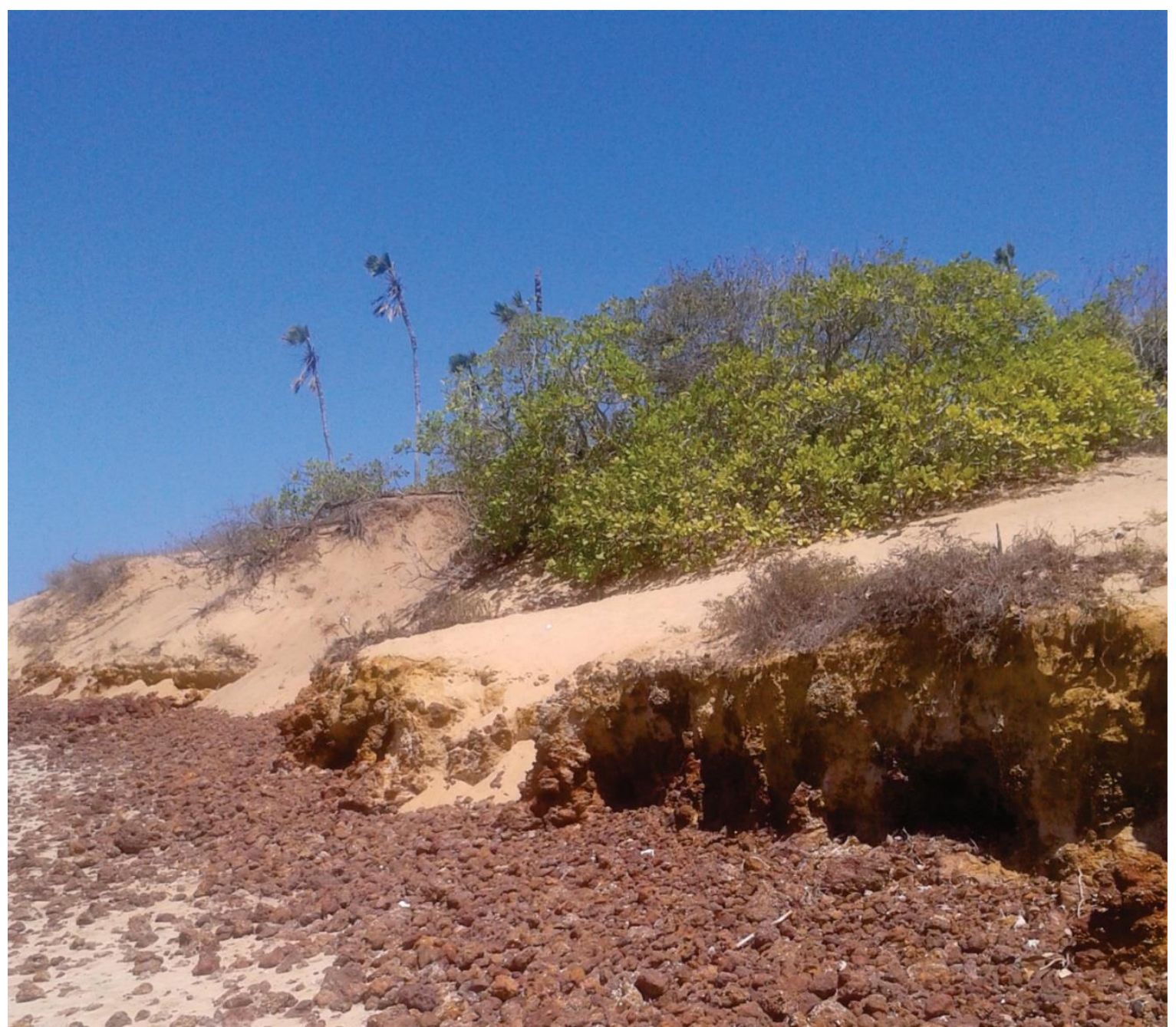

Figura 3: Aspectos da morfodinâmica na Falésia de Cajueiro da Praia. Fonte: Foto dos autores (2016). 
A morfodinâmica da falésia de Cajueiro da Praia segue um modelo cíclico, episódico em sua evolução, seguindo uma sequência básica de 3 etapas: (1) desprendimento de grãos ou blocos da face da falésia; (2) transporte e deposição na base da falésia, e (3) a remoção de detritos por processos marinhos (SILVA; LIMA, 2017).

Os processos erosivos que afetam a falésia de Cajueiro da Praia de forma preponderante são os marinhos e eólicos. Os primeiros têm como agentes as ondas, as marés e correntes costeiras, correspondendo a um processo natural que ocorre ao longo da linha de costa, provocando geralmente a recessão da falésia. Estas são cortadas para trás, formando enseadas e terraços de abrasão e, assim, quanto mais extrema a elevação da maré, maior o potencial de erosão, que muitas vezes é atenuado pelo seu extenso terraço de abrasão. Na área de estudo, esses agentes atacam a falésia apenas nas horas de maré alota, contribuindo para a formação de seu terraço de abrasão. O segundo tipo de erosão, a eólica, é provocada pelos ventos, principalmente no segundo semestre do ano, período em que a intensidade dos ventos se torna maior, causando desagregação e o transporte de partículas da face e do topo da falésia de Cajueiro da Praia. Um terceiro tipo de ataque à falésia é provocado pelos agentes climáticos, principalmente pelas precipitações e temperaturas, fazendo desencadear a formação de pequenos sulcos na face da falésia. É camada de erosão subárea, mas nessa falésia ocorre de forma menos intensa, em decorrência da sua pequena altura.

O terraço de abrasão formado na base da falésia é constituído principalmente por material solto, principalmente arenitos ferruginosos, que também podem ser chamados de arenitos de praia ou beach rocks. Estes são arredondados, com tamanhos diversos e conglomeráticos, variando de cerca de 2 a $20 \mathrm{~cm}$, formando agrupamentos de rochas longos e descontínuos sobre a praia, sendo cobertos parcial ou totalmente pela maré (Figura 4). 


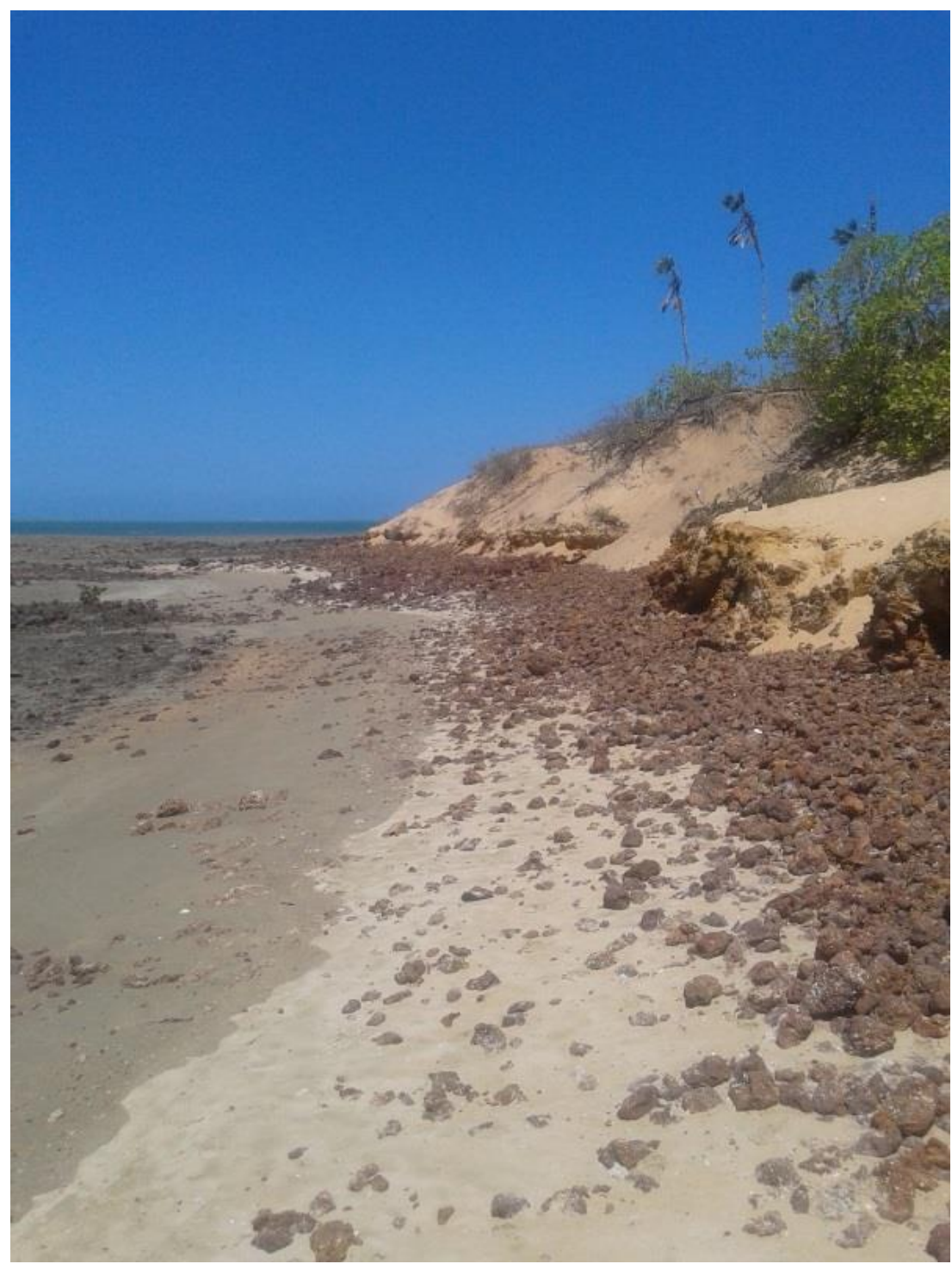

Figura 4: Terraço de Abrasão disposto ao longo da falésia de Cajueiro da Praia. Fonte: Foto dos autores (2016).

A coloração destes blocos de arenitos varia conforme a posição geográfica junto à linha da costa: mais distante - esverdeado e cinza; mais próximo - avermelhado, amarelado e cinza. O terraço de abrasão e consequentemente os arenitos ferruginosos, conformando recifes se encontram unidos à planície costeira, junto à falésia de Cajueiro da Praia, são oriundos da Formação Barreiras, e sofrem influência também dos cursos d'água próximos (BAPTISTA, 2010).

A análise petrográfica, realizada por Baptista (2010) indica serem arenitos conglomeráticos cimentados por óxido de ferro, o que contribui para a coloração que varia de marrom escuro a avermelhada. Apresentam granulação grossa, com estrutura maciça, sem deformações tectônicas, nem alterações intempéricas evidentes, sendo ainda coerentes. A maior concentração mineralógica se constitui em clastos de quartzo e quartzito (40\%) e óxidos/hidróxidos de ferro (15\%), que corresponde ao material que os cimenta (Figura 5), 
apresentando poros em pequena proporção (5\%). Os clastos maiores são também os mais arrendondados e esféricos e quase sempre são de quartzito (grãos policristalinos), enquanto os grãos menores de quartzo apresentam aspecto de grãos angulosos apresentando as bordas corroídas.

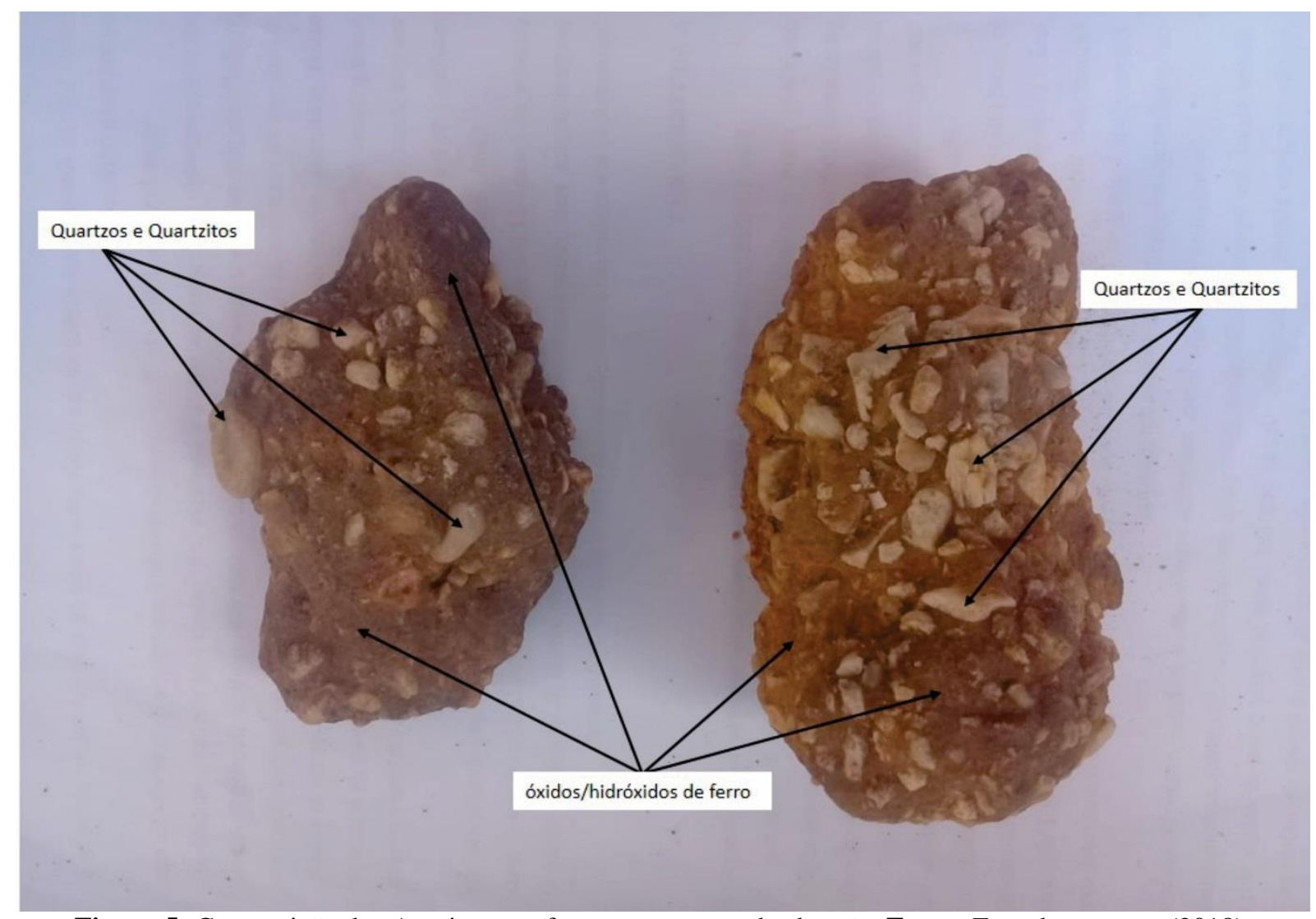

Figura 5: Composição dos Arenitos que formam o terraço de abrasão. Fonte: Foto dos autores (2018).

Com relação ao desgaste provocada por ações antrópicas, nessa área não foi observado nenhum tipo de uso ou ocupação humana e, portanto, ainda se encontra submetida somente à dinâmica ambiental natural do ambiente. Entretanto, a atual expansão da cidade de Cajueiro da Praia, em direção à praia, a partir da crescente atividade turística no litoral piauiense sem um planejamento de uso e ocupação da faixa costeira, se mostra preocupante principalmente pelo risco da não conservação das suas belas atrações naturais, dentre elas a falésia de Cajueiro da Praia, com o turismo pois pode afetar de maneira direta a falésia e consequentemente a dinâmica da área. 


\section{CONSIDERAÇÕES FINAIS}

A falésia de Cajueiro da Praia é uma geoforma única, um laboratório natural para uma série de pesquisas que envolvem desde oscilações do nível do mar a análises de ondas, correntes, marés, estudos petrográficas, geológicas, geomorfológicos e outros. Sua composição diferenciada, constituída pela Formação Barreiras e coberturas quaternárias arenosas reflete as condições ambientais da área.

A dinâmica marinha e o material constituinte contribuem significativamente para a ocorrência da evolução da falésia de Cajueiro da Praia, isto decorrente da energia das ondas, somadas à dinâmica de variação de marés, as correntes marinhas, provocando instabilidade no material e o desmonte progressivo de sua forma e deslocamento da linha de costa. A evolução da falésia de Cajueiro da Praia está associada, portanto, principalmente à erosão marinha, que influencia o ritmo de sua regressão e, consequentemente, a retrogradação da linha da costa local, testemunhada pela formação de extenso terraço de abração e recifes.

A influência do clima se processar em maior escala, através da atuação dos ventos, quando ocorre de forma predominante o desgaste do topo da falésia pela desagregação de partículas, decorrentes do material constituinte pouco coeso, o qual é deslocado para diversas áreas.

A formação de arenitos ferruginosos e terraço de abrasão formado principalmente por conglomerados, contendo quartzo, quartzito e óxido/hidróxido de ferro, são indicadores da influência marinha e fluvial local, demonstrando que não há um único elemento que comanda a dinâmica, mas uma serie deles, conformando um geossistema complexo.

Esta feição geomorfológica apresenta respostas que vão se refletir na sua forma e no seu ritmo de evolução, conforme as alterações ocorridas no tempo geológico, no fluxo de matéria e energia dos ambientes marinho e climático. Seu estudo é de suma importância, pois está se encontra em franca evolução natural e sua dinâmica encerra um frágil equilíbrio ambiental.

\section{REFERÊNCIAS}

AB'SABER, A.N. Litoral do Brasil. São Paulo: Metalivros, 2001.

BAPTISTA, E. M de C. Estudo morfossedimentar dos recifes de arenito da zona litorânea do estado do Piauí. 305 f. Tese (Doutorado). Programa de Pós-Graduação em Geografia. Universidade Federal de Santa Catarina: Florianópolis, 2010. 
BLOOM, A.L. Superfície da Terra. Blücher: São Paulo, 1970.

CAVALCANTI, A. P. B. Impactos e condições ambientais da zona costeira do Estado do Piauí. 341 f. Tese (Doutorado). Programa de Pós-Graduação em Geografia da Universidade Estadual Paulista. Rio Claro (SP), 2000.

CHRISTOFOLETTI, A. Geomorfologia. 2 ed. Blücher: São Paulo1980.

EMERY, K.O., KUHN, G.G. Sea cliffs: their processes, profiles, and classification. Geological Society of America Bulletin, 1982.

GUERRA, A. T.; GUERRA, A. J. T. Novo dicionário geológico-geomorfológico. 6. ed. Rio de Janeiro: Bertrand Brasil, 2008.

GUERRA, A.J.T., MARÇAL, M.S. Geomorfologia Ambiental. Bertrand Brasil: Rio de Janeiro, 2006.

LIMA, E. A. M.; BRANDÃO, R. L. Geologia. In: Pfaltzgraff, P. A. S.; Torres, F. S. M.; Brandão, R. L. (Org.). Geodiversidade do estado do Piauí. Recife: CPRM, 2010, p.15-24.

PAUlA, J. E de A. Dinâmica Morfológica da Planície Costeira do Estado do Piauí: evolução, comportamento dos processos costeiros e variação da linha de costa. $249 \mathrm{f}$. Tese (Doutorado). Programa de Pós-Graduação em Ciências Marinhas Tropicais. Universidade Federal do Ceará: Fortaleza, 2013.

PAULA, J. E. de A.; MORAIS, J. O.; BAPTISTA, E. M. de C.; GOMES, M. L.; PAULA, J. E. de A.; MORAIS, J. O.; BAPTISTA, E. M. de C.; GOMES, M. L.; PINHEIRO, L. de S. Piauí beach systems. In: SHORT, A. D.; KLEIN, A. H. F. (Editors). Brazilian Beach Systems. Austrália: Springer, 2016.

RODRIGUES, T. L. N.; ARAÚJO, C.C.; CAMAZZATO, E.; RAMGRAB, G.E. (Orgs.). São Luís, Folha SA-23-2-A, Cururupu, Folha SA-23-X-C, escala 1: 1.000.000. Brasília: Companhia de Pesquisa de Recursos Minerais, Programa Levantamentos Geológicos Básicos do Brasil, 1994.185 p.

ROSS, J. Ecogeografia do Brasil: subsídios para o planejamento ambiental. São Paulo: Oficina de Textos, 2006.

ROSSETI, D.F. Ambientes Costeiros. In: Florenzano, T. G. (org.). Geomorfologia: conceitos e tecnologias atuais. São Paulo: oficina de textos, 2008.

SILVA, C. H. S.; LIMA, I. M. M. F. Evolução geomorfológica recente da falésia de Itapari, São José de Ribamar-MA. Revista Brasileira de Geografia Física. v.10, n.06 (2017) 18591874.

Recebido em: 06/08/2019

Aceito para publicação em: 15/10/2019 